\title{
Olfactory and Gustatory Dysfunction in COVID-19 Patients: A Tertiary Care Institute Experience in India
}

\author{
Vishav Yadav ${ }^{1} \cdot$ Sanjeev Bhagat $^{1} \cdot$ Dinesh Kumar Sharma $^{1} \mathbb{C} \cdot$ Raminder Pal Singh Sibia $^{2}$. \\ Richa Pandav ${ }^{1}$. Ved Parkash Sandhu ${ }^{1}$
}

Received: 7 October 2020 / Accepted: 24 November 2020/Published online: 3 January 2021

(C) Association of Otolaryngologists of India 2021

\begin{abstract}
COVID-19 epidemic has varied spectrum of symptoms. With this study we aim to evaluate prevalence of Olfactory and Gustatory dysfunction in COVID-19 patients. To assess Olfactory and Gustatory dysfunction in COVID-19 Patients in Indian Population. Settings and Design: Prospective observational study. RT-PCR proven COVID-19 patients were enrolled in the study. Detailed history and olfactory function and Taste function were evaluated. Patient with symptoms of olfactory dysfunction were subjected to fill (sQOD-NS questionnaire). Re-evaluation was done weekly till the time of discharge. Analysis was done with Wilcoxon test with help of SPSS software. A total of 152 patients (Male-78, Female-74) completed the study after weekly evaluation. Olfactory and Gustatory dysfunction was seen in $28(18.41 \%)$ and 20 (13.15\%). Mean duration of symptoms was $2.4444 \pm 0.352$ days. Olfactory dysfunction was the first presenting symptom in
\end{abstract}

Dinesh Kumar Sharma

drdinesh11@gmail.com

Vishav Yadav

drvishavyadav@gmail.com

Sanjeev Bhagat

sbent224@gmail.com

Raminder Pal Singh Sibia

sibia1@yahoo.com

Richa Pandav

richapandav87@gmail.com

Ved Parkash Sandhu

sandhu15383@gmail.com

1 Department of ENT, Rajindra Hospital, Patiala, Punjab 147001, India

2 Department of Medicine, Rajindra Hospital, Patiala, Punjab 147001, India
11 out of 152 patients (7.23\%). Mean QD-NOS score in patients with Anosmia and Hyposmia (28 patients) was $11.4 \pm 2.01$ and $13.61 \pm 2.82$ at 1 st evaluation, $20.3 \pm 1.49$ and $20.33 \pm 1.57$ at 7 th day and 21 in both subgroups at 14th day follow up. Dysgeusia was noticed in 20/152 patients (13.15\%). Recovery in olfactory dysfunction and Dysgeusia was complete in all patients. Olfactory and gustatory dysfunctions are significant part of clinical spectrum of COVID-19 disease In Indian Population.

Keywords COVID-19 - Olfactory dysfunction ·

Anosmia $\cdot$ Hyposmia $\cdot$ Dysgeusia

\section{Introduction}

The Corona Virus disease 2019 (COVID-19) is an SARS$\mathrm{CoV} 2$ viral infection which started as local outbreak in Wuhan, China, soon became epidemic in China and later spread to rest of the world taking the form of Viral Pandemic [1]. Total 27, 973,127 cases and 9, 05, 426 deaths have been reported as per WHO Last update [2]. In India, More than 45, 68, 770 cases and more than 76,348 deaths have been reported so far [3].

Clinical presentation of COVID-19 patients vary from asymptomatic to common cold like symptoms i.e. nasal discharge, fever, nasal congestion to severe respiratory difficulty requiring assisted mechanical ventilation support [4]. Over the past 1 month, increasing number of researchers have reported COVID- 19 patients experiencing sudden Olfactory dysfunction (Anosmia/Hyposmia) and/or Dysgeusia/Altered taste sensation as presenting/concurrent/delayed symptoms of COVID-19 infection $[5,6]$. The centre for disease control and Prevention (CDC) has also added 'Altered Taste/smell sensation' to the 
COVID-19 presentation spectrum [7]. Various researchers from all over the world have reported olfactory dysfunction with widely varying incidence of $5.1 \%-74 \%$ [8-14]. So this study was conducted in RT-PCR confirmed COVID-19 patients in our hospital to evaluate the incidence of olfactory and gustatory dysfunction in COVID 19 patients.

\section{Material and Methods}

A prospective Observational study was conducted at Tertiary care institute, Government medical college and Rajindra Hospital, Patiala, India. All RT-PCR confirmed COVID-19 patients admitted in Institute from 1st March 2020 onwards were enrolled in the study. The following epidemiological and clinical symptoms were recorded: age, sex, co-morbidities, and general and otolaryngological symptoms with special reference to Olfactory and Gustatory symptoms. Institutional Ethical Committee approval was taken. Inclusion Criterion were patients with laboratory-confirmed COVID-19 infection, willing to participate in the study with consent. Exclusion Criterion were patients with Severe symptoms (SARI/Patient who need mechanical ventilation), Pregnant women, Children ( $<14$ years), Patients with dementia (who cannot report functional symptoms), Patients with previous long standing history of nasal obstruction, nasal discharge, nasal surgeries and patients who refused to give consent.

Patients were asked to complete Questionnaire consisted of questions regarding general symptoms; seven questions about olfactory function [Brief version of Questionnaire of Olfactory Disorders-Negative Statements (sQOD-NS)] [15]; four questions investigating gustatory/Taste function (salt/sweet/sour/bitter sensation). Brief version of the questionnaire of olfactory disorders-negative statements (sQOD-NS) (Table 1) is a seven-item patient-reported outcome questionnaire including social, eating, annoyance, and anxiety questions. Responses were reviewed (Improvement/ deterioration/ no change) at 7 days, 14 days and the time of discharge (if more than 14 days). Symptomatic patients were treated with Tab Hydroxychloroquine $400 \mathrm{mg} \mathrm{BD}$ for 1 day followed by $400 \mathrm{mg}$ for OD for 4 days, Tab Azithromycin $500 \mathrm{mg}$ OD for 5 days and Tab Paracetamol $500 \mathrm{mg}$ sos. No specific treatment pertaining to olfactory and salivatory dysfunction was given Patient were discharged after patient became asymptomatic and two samples (nasopharyngeal and oropharyngeal swabs) on 2 consecutive days came negative on RT-PCR testing for COVID-19.

\section{Results}

A total of 203 patients of COVID-19 were admitted in COVID-19 Isolation facility. 30 patients of severe acute respiratory infection (SARI) on mechanical ventilation, 16 paediatric patients of age $<14$ years and 5 pregnant females were excluded from the study. Total 152 patients were included in the study group with 78 (51.3\%) male patients and $74(48.7 \%)$ female patients. Age of the study group was in the range of 14-77 years, with mean $43.03 \pm 16.10$ years. Pre-existing co-morbidities data was collected and studied (Fig. 1). Patients were enquired about symptoms in detail e.g. cough, fever, loss of appetite, myalgia, respiratory difficulty, diarrhoea, headache (Fig. 2) and ENT symptoms: dryness of throat, soreness of throat, posterior nasal discharge and rhinorrhea (Fig. 3). 78 patients didn't report any symptom at all.

Table 1 Brief version of the questionnaire of olfactory disorders-negative statements (sQOD-NS)

\author{
Social questions \\ The changes in my sense of smell make me feel isolated \\ Because of the changes in my sense of smell, I have problems with taking part in activities of daily life \\ The changes in my sense of smell make me feel angry \\ Eating questions \\ Because of the changes in my sense of smell, I go to restaurants less often than I used to \\ Because of the changes in my sense of smell, I eat less than I used to or more than I used to \\ Anxiety questions \\ Because of the changes in my sense of smell, I try harder to relax \\ Annoyance questions \\ I am worried that I will never get used to the changes in my sense of smell
}

Each item is rated on a scale of $0-3$, with higher scores reflecting better olfactory-specific QOL. The total score ranges from 0 (severe impact on QoL) to 21 (no impact on QoL) 
Fig. 1 Prexisting comorbidities in the COVID-19 patients

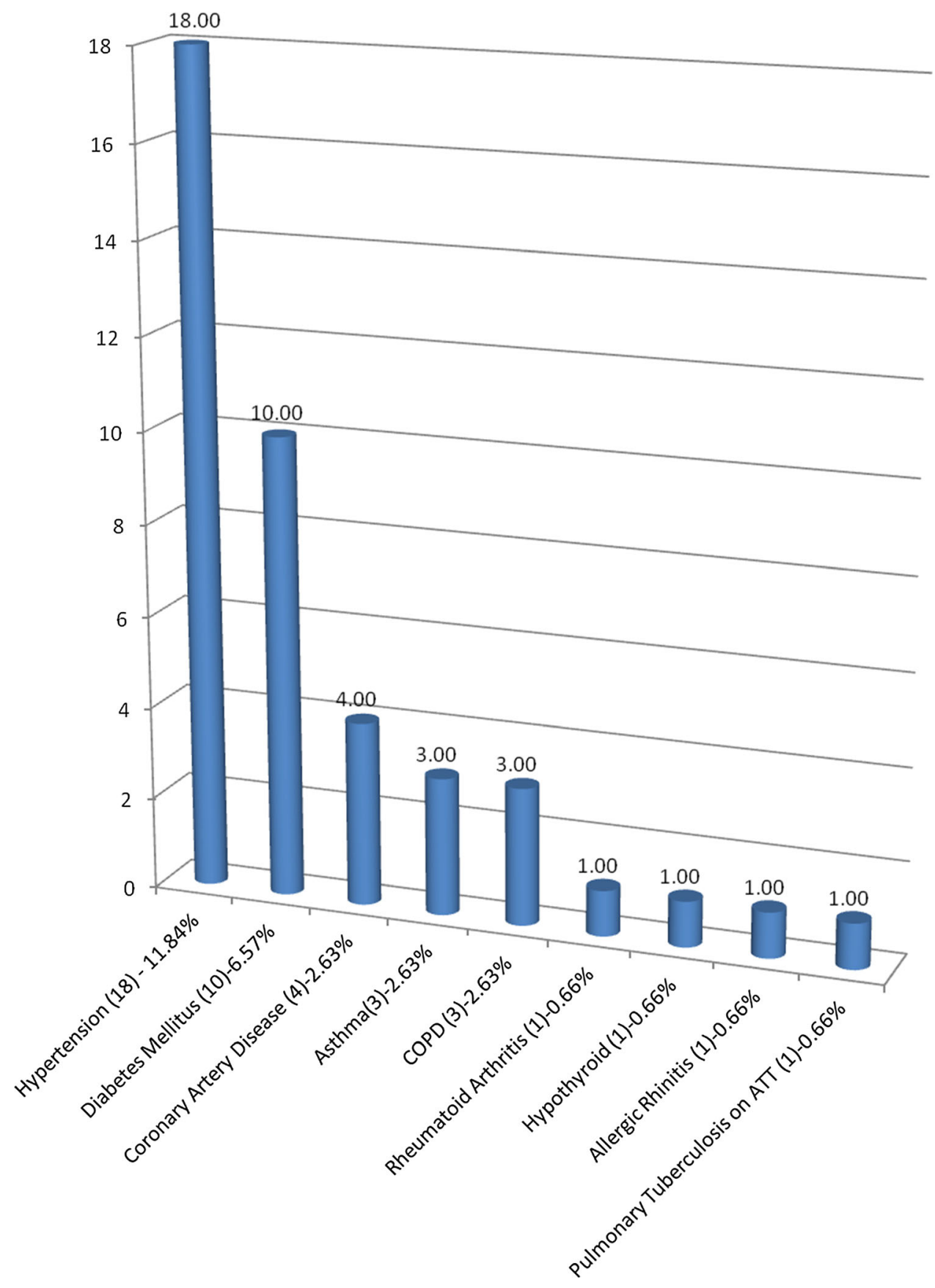

\section{Olfactory Dysfunction}

Olfactory dysfunction (Table 2) was reported in the 28 out of 152 patients $(18.42 \%)$ with anosmia in $10(6.58 \%)$ and hyposmia in 18 patients (11.84\%). However among the 74 symptomatic patients, olfactory dysfunction was seen in $37.83 \%$ of subjects.

Out of 152 patients, $13(8.55 \%)$ had Olfactory dysfunction and Dysgeusia, $15(9.86 \%)$ patients had isolated olfactory dysfunction. QD-NOS was assessed in 28/152 patients (18.42\%). QDNOS score in Anosmia and Hyposmia was $11.4 \pm 2.01$ and $13.61 \pm 2.82$ at 1 st evaluation (time of admission), $20.3 \pm 1.49$ and $20.33 \pm 1.57$ at 7 th day and 21 in both subgroups at 14th day follow up. Improvement noticed in QDNOS score was found to be statistically highly significant $(p<0.001)$. Recovery in olfactory dysfunction with as per QD-NOS was seen in $23 / 28(82.14 \%)$ at 7 th day, rest of 5 recovered by the 14 th day follow up. There was complete recovery of olfactory dysfunction seen in all of the patients by 14 days. 
Fig. 2 Summarization of general symptoms associated with COVID-19 patients

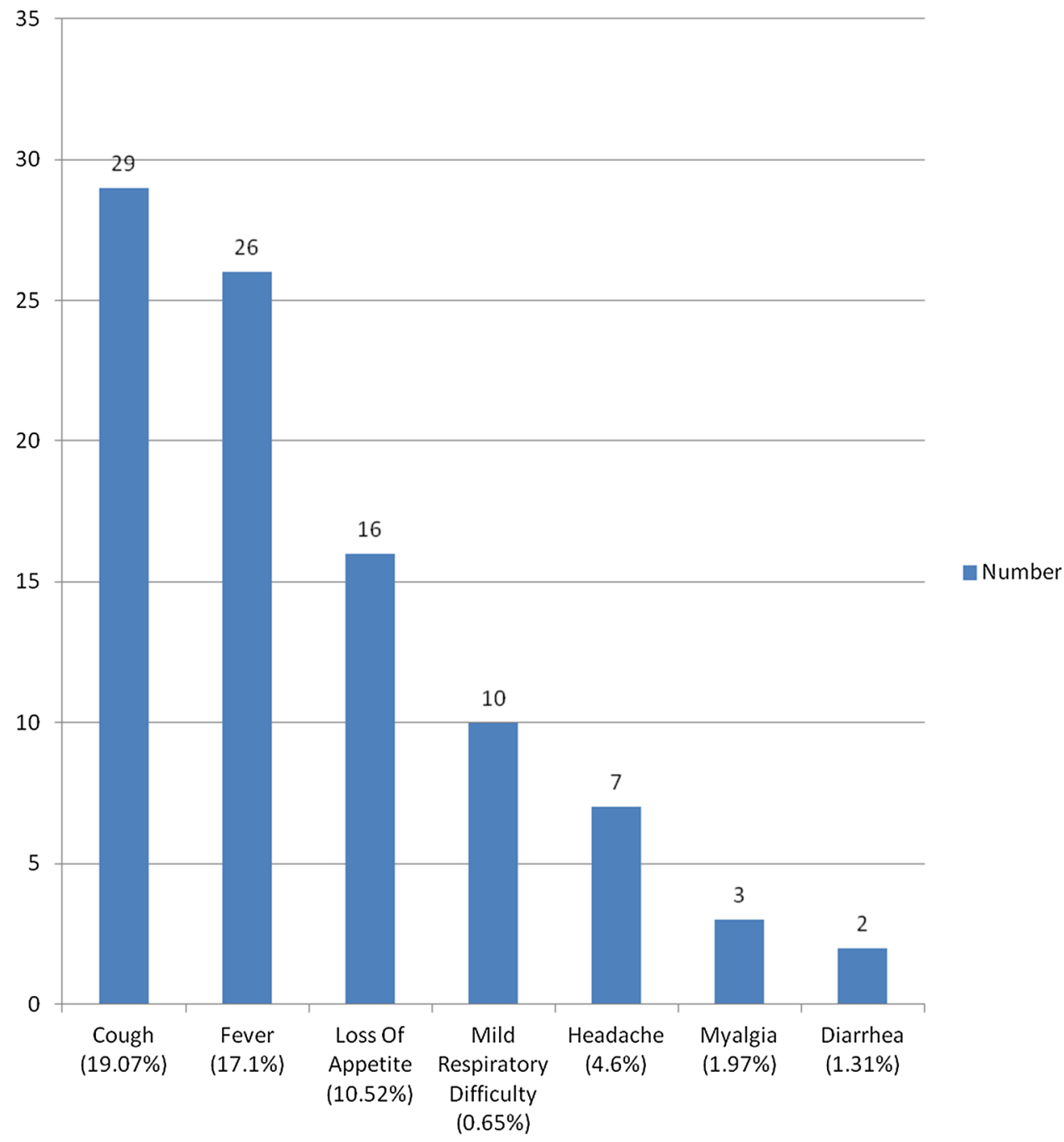

\section{Dysgeusia}

Dysgeusia was noticed in 20/152 (13.15\%) (Fig. 4). Among 74 symptomatic patients, incidence was noted to be $27.02 \%$. 17 patients (85\%) had loss of all 4 taste stimuli, 2 patients $(10 \%)$ had loss of salt and sweet sensation, 1 patient $(5 \%)$ had loss of only sweet sensation. Dysgeusia symptoms have been illustrated in detail in Fig. 4. At 7th day evaluation, Recovery was seen in 11/20 (55\%). Complete recovery was in $100 \%$ at 14 th day evaluation.

\section{Discussion}

Over the past months, various studies from Europe, Asia and rest of the world have been reported regarding olfac- tory and gustatory dysfunctions in COVID-19 patients with variable incidence.

The mean age of our population was $43.03 \pm 16.10$ years. Out of $152,51.3 \%$ were males and $48.7 \%$ were females. However Lechien JR et al. [8] and Timothee Klopfenstein et al. [9] studies had reported higher incidence in female patients: $63 \%$ and $67 \%$ respectively.

Timothée Klopfenstein et al. study observed a mean duration of anosmia of 9 days.In our study, Mean duration of anosmia/hyposmia was $2.4444 \pm 0.352$ days [Range: 1-4 days].

Lechien et al. [8] and Kaye et al. [5] observed olfactory dysfunction as the first symptom in $11.8 \%$ and $26.6 \%$ respectively. We reported olfactory dysfunction (Anosmia/ Hyposmia) as presenting symptom in 11 out of 74 symp- 
Fig. 3 ENT symptoms in COVID-19 patients

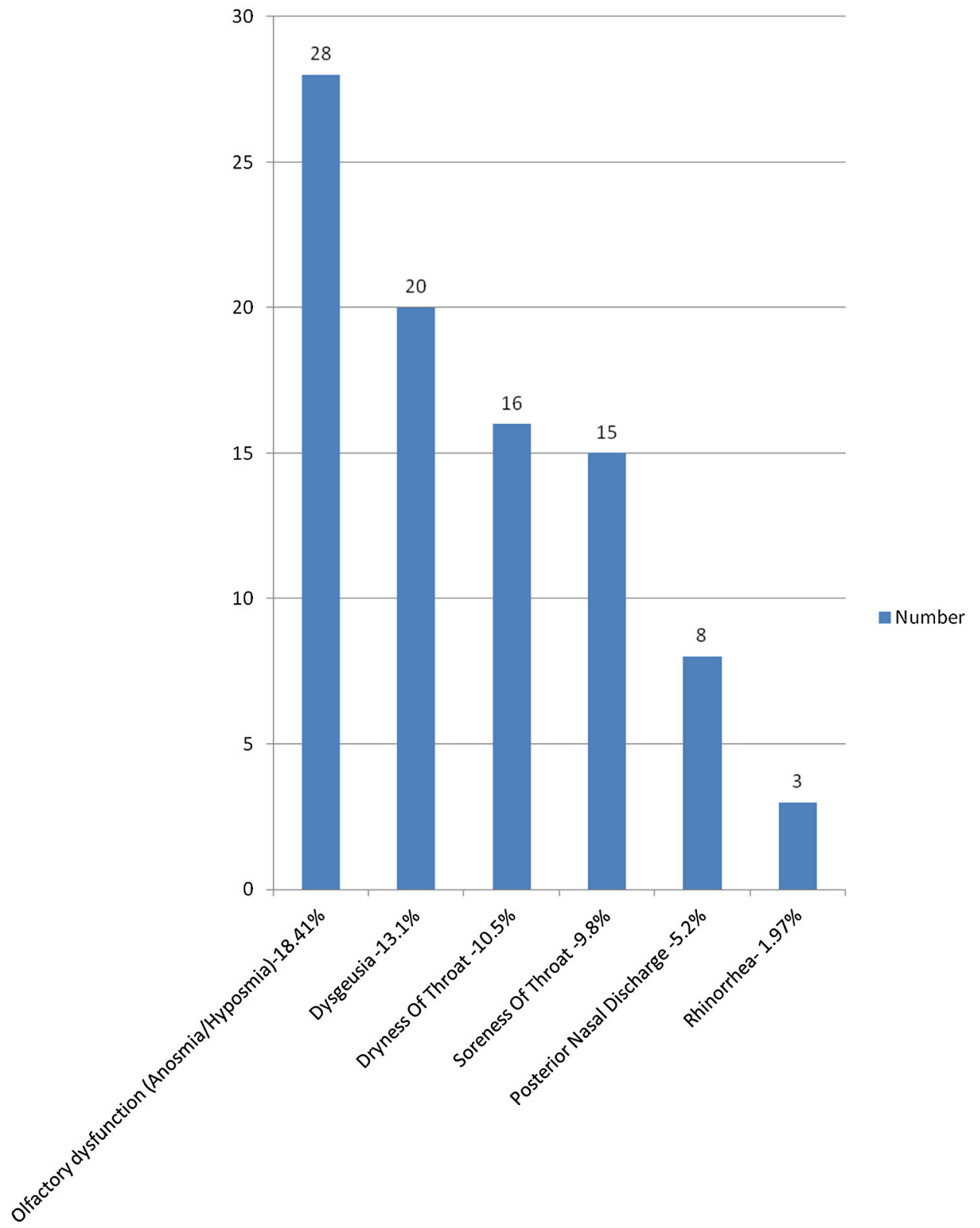

tomatic patients $(14.86 \%)$, along with other symptoms in $13 / 74(17.57 \%)$ patients, appeared after other symptoms in $4 / 74(5.4 \%)$ patients. So the olfactory dysfunction may be the only presenting symptom in COVID-19 patients.

Lechien et al. [8] and Timothée Klopfenstein et al. [9] reported olfactory dysfunction in $86 \%$ (357/417) and $47 \%$ (54/114) of symptomatic patients respectively. Vaira et al. [10] study on 72 subjects reported olfactory dysfunction in $61.1 \%(44 / 72)$ of cases. Yan et al. [11] reported olfactory dysfunction in $68 \%$ in the study group (59 subjects). Luers et al. [6] reported olfactory dysfunction in $74 \%$ (53/72) of patients. In our study, olfactory dysfunction was reported in the 28 out of 74 symptomatic patients $(37.83 \%)$. Our results are comparable with above mentioned studies. In contrast Mao et al. [12] reported the incidence of hypogeusia in $5.6 \%$ and hyposmia in $5.1 \%$. Giacomelli et al. [13] reported a study on 59 patients, 20 (33.9\%) reported at least 1 taste or olfactory disorder and 11 (18.6\%) both. Vaira et al. [14] reported chemosensory dysfunction in $19.4 \%$ out of 320 patients.

Wide variation in above reported literature may be attributed to pathophysiology of nCoV-2 infection. Suzuki et al. [16] in 2008 reported Corona virus as pathogen to cause post viral Olfactory Dysfunction. Peng Zhou et al. [17] identified the role of Angiotensin converting enzyme 2 (ACE2) in the pathogenesis of SARS-CoV-2. Brann DH 
Table 2 Details of Olfactory dysfunction in COVID-19 patients

\begin{tabular}{llll}
\hline & & Number & $\%$ age \\
\hline 1 & Anosmia + Hyposmia & $28 / 152$ (Total) & $18.42 \%$ \\
& & $28 / 74$ (Symptomatic) & $37.83 \%$ \\
& Anosmia & 10 & $6.58 \%$ \\
& Hyposmia & 18 & $11.84 \%$ \\
2 & Mean duration (days) & $2.4444 \pm 0.352$ & $\%$ age \\
4 & Range 5 & $1-4$ days & $14.86 \%$ \\
& Timing of Olfactory Dysfunction & Number & $17.57 \%$ \\
& First symptom & $11 / 74$ & $5.4 \%$ \\
& Concomitant & $13 / 74$ & $8.55 \%$ \\
6 & Later than general symptoms & $4 / 74$ & 7 days \\
& Olfactory dysfunction association with dysgeusia & $13 / 152$ & $20.3 \pm 1.49$ \\
& Mean QDNOS Score in 28 patients & 1 st evaluation & $20.33 \pm 1.57$ \\
\hline
\end{tabular}

Fig. 4 Dysgeusia was present in $20 / 152$ patients $(13.15 \%)$ out of 20, $17(85 \%)$ patients hadloss of all 4 taste stimuli, 2 patients (10\%)- salt and sweet, 1 patients (5\%)- sweet

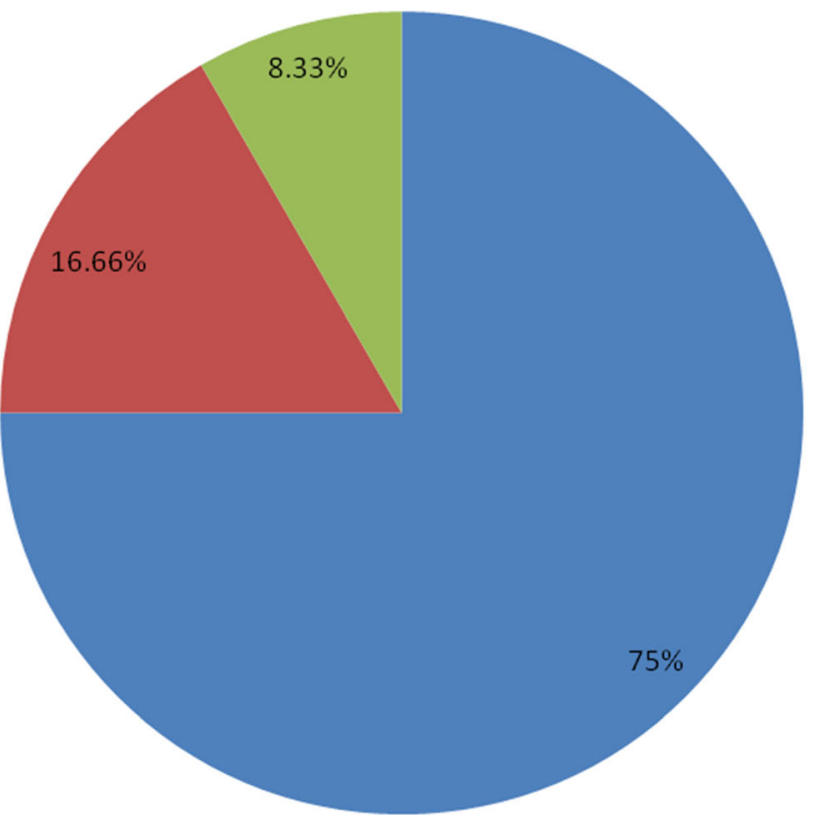

Salt, Sweet, Sour, Bitter

Salt and Sweet

Sweet et al. [18] studied and explained the role of 2 genes: ACE2 and TMPRSS in olfactory epithelial support cells, stem cells, and nasal respiratory epithelium explaining the possible mechanism of anosmia in COVID-19 patients. These 2 genes play a potential role in transport of SARS-CoV-2 into the cell. Netland et al. [19] also reported the potential role of SARS-CoV receptor (human ACE 2) in transneuronal spread of virus to olfactory bulb region. Yanan Cao et al. [20] reported expression quantitative trait loci (eQTLs) variants of the ACE2 gene which can be a cause for ACE2 polymorphisms and ACE2 expression levels between Asian and European populations. It can be one of possible aetiology in variety of expression in olfactory dysfunction in different countries or races. However its exact aetiology is a matter of further detailed research to confirm ACE 2 receptors role.

Recovery in olfactory dysfunction with assessment by QD-NOS was seen in 19/28 (67.86\%) at 1 week, rest 9 recovered from olfactory dysfunction by the end of total 14 days, so complete recovery of olfactory dysfunction was seen in $100 \%$ of patients by 14 days. Lechien et al. reported $72.6 \%$ of patients recovered olfactory function within the first 8 days following the resolution of the disease. Timothée Klopfenstein et al. also reported ansomia 
recovery in $80 \%$ of patients recovered within 14 days. Lee et al. [21] reported recovery in $80 \%$ of Patients with postviral olfactory loss within 1 year.

Lechien et al. [8] observed olfactory dysfunction was not significantly associated with Nasal discharge or nasal obstruction. In our study, 8/28- olfactory dysfunction group (28.57\%) had associated posterior nasal discharge and 3/28 $(10.7 \%)$ patients had associated rhinorrhea. However this association was found not to be statistically significant.

Lechien et al. [8] and Klopfenstein et al. [9], both observed diarrhoea in $>50 \%$ of patients. But as per our data, no patient with olfactory dysfunction had associated diarrhoea complaint.

In 12 patients of COVID-19 with Hypertension and in 7 patients of COVID-19 with Diabetes Mellitus 2, olfactory dysfunction was seen in 4 patients $(33.33 \%)$ and 5 patients (71.42\%) respectively. Because of small sample size, it was not possible to evaluate statistically correlation between COVID-19 with associated co-morbidity Hypertension / Diabetes and Olfactory dysfunction.

Dysgeusia was present in 20/152 patients (13.15\%). At 7th day evaluation, recovery in dysgeusia was seen in $13 / 20(65 \%)$. Recovery was noticed in rest of the patients at 14th day follow up. Giacomelli et al. [13] observed taste dysfunction in $10.2 \%$ of subjects.

The strength of our study is that it is a prospective study of the true cohort of COVID-19 patients in Indian population as all patients with RT-PCR confirmed COVID-19 were admitted in our hospital irrespective of presence/absence of symptoms. So our study group is a true representation of COVID-19 cohort which eliminates the bias of not including or missing out asymptomatic/mildly symptomatic patients who don't need admission in hospital. Our study limitations are small sample size and being an observational study, our study didn't benefit in improvement in treatment. However, to best of our knowledge this is the first Indian single centre cohort study of confirmed COVID-19 patients to evaluate olfactory and gustatory dysfunction.

\section{Conclusion}

Olfactory and gustatory dysfunctions are significant part of spectrum of COVID-19 symptoms in Indian population. Sudden onset anosmia/hyposmia with or without taste sense dysfunction can be the presenting symptom of the COVID-19. So Otolaryngologists and other medical specialty colleagues need to be extra vigilant about the symptoms of olfactory/gustatory dysfunction to diagnose COVID-19 patients at an early stage. Olfactory and Dysgeusia symptoms are transient and fully recoverable.

\section{References}

1. Guan WJ, Ni ZY, Hu Y et al (2020) Clinical characteristics of coronavirus disease 2019 in China. N Engl J Med. https://doi.org/10.1056/NEJMoa2002032

2. WHO COVID-19 website. https://covid19.who.int/

3. Indian COVID 19 Dashboard. https://www.covid19india.org/

4. Wu Z, McGoogan JM (2020) Characteristics of and important lessons from the coronavirus disease 2019 (COVID-19) outbreak in China: summary of a report of 72,314 cases from the Chinese center for disease control and prevention. JAMA 323(13):1239-1242. https://doi.org/10.1001/jama.2020.2648

5. Kaye R, Chang CWD, Kazahaya K, Brereton J, Denneny JC III (2020) COVID-19 anosmia reporting tool: initial findings. Otolaryngol Head Neck Surg 28:194599820922992. https://doi.org/10.1177/0194599820922992

6. Luers JC, Rokohl AC, Niklas L, Wawer Matos PA, Augustin M, Dewald F, Klein F, Lehmann C, Heindl LM (2020) Olfactory and gustatory dysfunction in coronavirus disease 19 (COVID-19). Clin Infect Dis. https://doi.org/10.1093/cid/ciaa525

7. Centers for Disease Control and Prevention (2020) Coronavirus disease 2019 (COVID-19)—symptoms. Published April 17, 2020. https://www.cdc.gov/coronavirus/2019-ncov/symptoms-testing/ symptoms.html Accessed 22 Apr 2020

8. Lechien JR, Chiesta-Estomba CM, De Siati DR, Horoi M, Le Bon SD, Rodriguez A, Dequanter A, Dequanter D, Blecic S, El Afia F, Distinguin L, Chekkoury-Idrissi Y, Hans S, Delgado IL, CalvoHenriquez C, Lavigne P, Falanga C, Barillari MR, Cammaroto G, Khalife M, Leich P, Souchay C, Rossi C, Journe F, Hsieh J, Edjlali M, Carlier R, Rise L, Lovato A, De Filippis C, Coppee F, Fakhry N, Ayad T, Saussez S (2020) Olfactory and gustatory dysfunctions as a clinical presentation of mild-to-moderate forms of the coronavirus disease (COVID-19): a multicenter European study. Eur Arch Otorhinolaryngol. https://doi.org/10.1007/s004 05-020-05965-1

9. Klopfenstein T, Kadiane-Oussou NJ, Toko L, Royer PY, Lepiller Q, Gendrin V, Zayet S (2020) Features of anosmia in COVID-19. Med et Mal Infect. https://doi.org/10.1016/j.medmal.2020.04.006

10. Vaira LA, Deiana G, Fois AG et al (2020) Objective evaluation of anosmia and ageusia in COVID-19 patients: a single-center experience on 72 cases. Head Neck. https://doi.org/10.1002/H ED.26204

11. Yan CH, Faraji F, Prajapati DP, Boone CE, DeConde AS (2020) Association of chemosensory dysfunction and Covid-19 in patients presenting with influenza-like symptoms. Int Forum Allergy Rhinol. https://doi.org/10.1002/alr.22579

12. Mao L, Wang M, Chen S et al (2020) Neurological manifestations of hospitalized patients with COVID-19 in Wuhan, China: a retrospective case series study. MedRXiv. https://doi.org/10.11 01/2020.02.22.20026500

13. Giacomelli A, Pezzati L, Conti F, Bernacchia D, Siano M, Oreni RS, Gervasoni C, Ridolfo A, Rizzardini G, Antinori S, Galli M (2020) Self-reported olfactory and taste disorders in SARSCoV-2 patients: a cross-sectional study. Clin Infect Dis. https://doi. org/10.1093/cid/ciaa330

14. Vaira LA, Salzano G, Deiana G, De Riu G (2020) Anosmia and ageusia: common findings in COVID-19 patients. Laryngoscope. https://doi.org/10.1002/lary.28692

15. Mattos JL, Edwards C, Schlosser RJ et al (2019) A brief version of the questionnaire of olfactory disorders in patients with chronic rhinosinusitis. Int Forum Allergy Rhinol 9(10):1144-1150. https://doi.org/10.1002/alr.22392

16. Suzuki M, Saito K, Min WP, Vladau C, Toida K, Itoh H, Murakami S (2007) Identification of viruses in patients with postviral 
olfactory dysfunction. Laryngoscope 117(2):272-277. https://doi. org/10.1097/01.mlg.0000249922.37381.1e

17. Zhou P, Yang XL, Wang XG et al (2020) A pneumonia outbreak associated with a new coronavirus of probable bat origin. Nature 579:270-273. https://doi.org/10.1038/s41586-020-2012-7

18. Brann DH, Tsukahara T, Weinreb C et al (2020) Nonneural expression of SARS CoV entry genes in the olfactory epithelium suggests mechanisms underlying anosmia in COVID patients. BioRxiv. https://doi.org/10.1101/2020.03.25.009084

19. Netland J, Meyerholz DK, Moore S, Cassell M, Perlman S (2008) Severe acute respiratory syndrome coronavirus infection causes neuronal death in the absence of encephalitis in mice transgenic for human ACE2. J Virol 82(15):7264-7275. https://doi.org/ 10.1128/JVI.00737-08
20. Cao Y, Li L, Feng Z, Wan S, Huang P, Sun X, Wen F, Huang X, Ning G, Wang W (2020) Comparative genetic analysis of the novel coronavirus (2019-nCoV/SARS-CoV-2) receptor ACE2 indifferent populations. Cell Discov 6:11. https://doi.org/10.103 8/s41421-020-0147-1

21. Lee DY, Lee WH, Wee JH, Kim J-W (2014) Prognosis of postviral olfactory loss: follow-up study for longer than one year. Am J Rhinol Allergy 28(5):419-422. https://doi.org/10.2500/aj ra.2014.28.4102

Publisher's Note Springer Nature remains neutral with regard to jurisdictional claims in published maps and institutional affiliations. 